\title{
Aquele que "salva" a mãe e o filho*
}

\section{Ana Lucia Araujo**}

O artigo busca reconstruir o mito do mercador de escravos Francisco Félix de Souza (1754-1849). A partir de fontes textuais, entrevistas realizadas com membros da família e do exame do memorial de Francisco Félix de Souza, analisa-se a reconstrução da memória do mercador no seio da família. Ao mesmo tempo, tenta-se entender como a memória do ancestral exprime as implicações políticas associadas à memória da escravidão no Benim contemporâneo.

Palavras-chave: memória, comércio atlântico de escravos, Francisco Félix de Souza

\section{The One Who Rescues the Mother and the Child}

This paper aims to reconstruct the myth surrounding the Brazilian slave merchant Francisco Félix de Souza (1754-1849). Relying on the exam of textual sources, interviews with family members as well as the examination of Francisco Félix de Souza's memorial, the article analyzes the reconstruction of the memory of the slave merchant within his family. At the same time, it aims at understanding how the memory of the ancestor expresses the political issues related to the memory of slavery in the contemporary Benin.

\footnotetext{
${ }^{*}$ Recebido e aprovado para publicação em janeiro de 2010. Uma versão prévia deste artigo, mais longa e distinta, foi publicada em francês sob o título "Enjeux politiques de la mémoire de l'esclavage dans l'Atlantique Sud: La reconstruction de la biographie de Francisco Félix de Souza", Lusotopie, vol. XVI, n. 2, 2009, p. 107-131. Outra versão ligeiramente modificada deste artigo será publicada sob o título "Forgetting and Remembering the Atlantic Slave Trade: The Legacy of the Brazilian Slave Merchant Francisco Felix de Souza", in Ana Lucia Araujo, Mariana P. Candido e Paul Lovejoy, org., Crossing Memories: Slavery and African Diaspora, Trent, NJ, Africa World Press, no prelo.

**Department of History, Howard University, Washington DC, EUA. E-mail: aaraujo@howard.edu
} 
Keywords: memory, Atlantic slave trade, Francisco Félix de Souza

\section{Celui qui "sauve" la mère et l'enfant}

L'article cherche à reconstruire le mythe autour du marchand d'esclaves Francisco Félix de Souza (1754-1849). À partir de sources textuelles, d'entretiens réalisés auprès des membres de la famille et de l'examen du mémorial de Francisco Félix de Souza, l'article analyse la reconstruction de la mémoire du marchand au sein de la famille. En même temps, il cherche également à comprendre comment la mémoire de l'ancêtre constitue l'expression des enjeux politiques associés à la mémoire de l'esclavage dans le Bénin contemporain.

Mots-clé: mémoire, commerce atlantique des esclaves, Francisco Félix de Souza

Durante a primeira metade do século XIX, o mercador de escravos Francisco Félix de Souza (1754-1849) desenvolveu o comércio de escravos entre o Brasil e o Reino do Daomé, situado na Costa dos Escravos, na África Ocidental, onde hoje se situa a República do Benim. Desde os anos 1960, a vida e a carreira do mercador brasileiro têm sido objeto de estudos desenvolvidos por vários historiadores como David Ross, Robin Law e Alberto da Costa e Silva. ${ }^{1}$ No entanto, esses estudiosos não se debruçaram sobre a inserção do personagem no fenômeno de patrimonialização da escravidão e do comércio atlântico de africanos escravizados que se desenvolveu no Benim durante os últimos anos, através de projetos oficiais liderados em grande parte pela UNESCO. Este processo teve por resultado promover a memória pública do mercador brasileiro, dando-lhe mais visibilidade no espaço público. Mais do que avançar simples fatos, o estudo da biografia de Francisco Félix de Souza nos oferece pistas metodológicas para lidar com a antiga oposição entre a tradição oral e as fontes escritas, questionando assim a relação entre a memória e a escritura da história.

\footnotetext{
${ }^{1}$ David Ross, "The First Chacha of Whydah: Francisco Félix de Souza", Odu, vol. 2, 1969, p. 19-28; Robin Law, "A carreira de Francisco Félix de Souza na África Ocidental (1800-1849)", Topoi, 2001, p. 9-39; Alberto da Costa e Silva, Francisco Félix de Souza, mercador de escravos, Rio de Janeiro, Nova Fronteira, 2004.
} 
Recentemente, Robin Law questionou o papel político e econômico crucial usualmente atribuído a Francisco Félix de Souza na história do Benim. ${ }^{2}$ A imagem de Souza parece desproporcional em relação ao seu peso real no comércio de escravos na Baía do Benim. Mesmo se novas fontes indicam que vários outros mercadores eram mais prósperos, de Souza continua a ocupar um lugar central na memória do tráfico atlântico de escravos não somente no Benim, mas também em todo o Atlântico Sul. Baseados nesses dados podemos nos perguntar quais foram os elementos que permitiram que a memória do mercador sobrevivesse. Por que e como Francisco Félix de Souza se tornou um símbolo das trocas entre a Bahia e a Baía do Benim? Como essa identidade se tornou um mito fundador e uma referência para a comunidade afro-lusobrasileira do Benim? Como a memória coletiva e familiar conseguiu associar o papel de mercador de escravos ao papel de filantropo? Que papel tem o Brasil na reconstrução do mito de Francisco Félix de Souza? Um exame das fontes orais e escritas, juntamente com uma visita ao memorial de Francisco Félix de Souza localizado em Singbomey, complexo residencial da família situado na antiga cidade portuária escravista de Ajudá, no Benim, ajudará a responder a estas perguntas.

\section{A memória da escravidão e sua patrimonialização}

No começo dos anos 1990, a patrimonialização da escravidão e do tráfico atlântico de escravos se constitui como um movimento transnacional que ultrapassou os limites das Américas e da Europa e chegou até a África, onde adquiriu contornos particulares. No Benim, a emergência do debate sobre o passado escravista foi acompanhada por uma série de projetos oficiais, desenvolvidos pelo governo do país e também por agências internacionais como a UNESCO ou ainda por organizações não governamentais. Nesse contexto, até mesmo as elites locais, cuja história estava relacionada com o comércio de escravos, passaram a participar desse movimento de patrimonialização da escravidão. Vários descendentes de mercadores de escravos brasileiros e portugueses, juntamente com descendentes de antigos escravos que retor-

${ }^{2}$ Law, "A carreira de Francisco Félix de Souza na África Ocidental (1800-1849)"; Law, "The Atlantic Slave Trade in Local History Writing in Ouidah", in Naana Opoku-Agyemang, Paul E. Lovejoy e David V. Trotman, org., Africa and Trans-Atlantic Memories: Literary and Aesthetic Manifestations of Diaspora and History, Trenton, NJ, Africa World Press, 2008; Robin Law, Ouidah, The Social History of a West African Slaving Port, 1727-1892, Athens, Ohio University Press, 2004. 
naram do Brasil para a África Ocidental, passaram a promover seu passado escravo no espaço público, contribuindo assim para o sucesso do fenômeno de patrimonialização.

O surgimento da memória pública da escravidão no Benim está relacionado às comemorações dos quinhentos anos da chegada de Cristóvão Colombo nas Américas. Naquela época, por volta de 1990, discutia-se o fato de que o comércio atlântico de africanos escravizados e sua contribuição para a construção das Américas tinham recebido pouca atenção da parte do comitê que organizava as comemorações. Esse debate deu lugar a dois projetos distintos: um projeto científico transnacional intitulado "A Rota do Escravo" e o festival Ouidah 92: Festival mondial des cultures vaudou: retrouvailles Amériques-Afriques (“Ajudá 92: Festival mundial das culturas vodu: reunião Américas-Áfricas”), cujos focos eram respectivamente o desenvolvimento do turismo e as religiões africanas ditas tradicionais. No final das discussões, os dois projetos foram praticamente combinados e ambos receberam o apoio da UNESCO e do governo do Benim. ${ }^{3}$

Em 1991, após mais de vinte anos de ditadura marxista-leninista, tiveram lugar, no Benim, eleições presidenciais, que levaram ao poder Nicéphore Soglo. O novo governo procurou não somente promover a liberdade religiosa, mas também desenvolver a economia nacional atraindo turistas para o país. Nesse contexto, tanto a religião vodun como o comércio atlântico de africanos escravizados se tornaram o foco de vários programas cujo objetivo era promover o turismo cultural no país. ${ }^{4}$ Esses novos projetos valorizaram patrimônio material e imaterial do comércio de escravos através de diferentes formas de comemorações, da construção de monumentos e da criação de museus de família. Ambos os projetos foram bastante controvertidos e deram lugar a um debate importante nos jornais locais. ${ }^{5}$

Em Ajudá, é possível identificar as múltiplas dimensões da memória da escravidão que se manifesta de um lado através dos descendentes de es-

\footnotetext{
${ }^{3}$ Emmanuelle Kadya Tall, "De la démocratie et des cultes voduns au Bénin", Cahiers d'études africaines, n. 137, 1995, p. 195-208; Ana Lucia Araujo, "Mémoires de l'esclavage et de la traite des esclaves dans l'Atlantique Sud: enjeux de la patrimonialisation au Brésil et au Bénin”, tese de doutorado, Université Laval e École des Hautes Études en Sciences Sociales, 2007.

${ }^{4}$ Suzanne Preston Blier, African Vodun: Art, Psychology, and Power, Chicago, University of Chicago Press, 1995, p. 4.

${ }^{5}$ Tall, "De la démocratie et des cultes voduns au Bénin"; Nassirou Bako-Arifari, "La mémoire de la traite négrière dans le débat politique au Bénin dans les années 1990”, Journal des Africanistes, vol. 70, n. 1-2, 2000, p. 221-231; Araujo, "Mémoires de l'esclavage et de la traite des esclaves dans l'Atlantique Sud", p. 156.
} 
cravos e de outro lado através dos descendentes de mercadores de escravos de origem brasileira e portuguesa, assim como de seus colaboradores, que também participaram no comércio. A memória se inscreve na paisagem física e política da cidade e do país, dividido por conflitos memoriais que nem sempre são visíveis aos olhos dos turistas que visitam as cidades costeiras. Nesse contexto, a família do mercador de escravos Francisco Félix de Souza, que ainda ocupa uma posição social importante em Ajudá, tem exercido um papel fundamental no movimento de patrimonialização da escravidão. No entanto, essa situação acabou gerando uma série de ambiguidades, pois se em princípio os projetos oficiais eram destinados a valorizar a memória das vítimas do comércio de escravos, esses objetivos iniciais foram gradualmente sendo desviados para atender as necessidades das elites locais. Como resultado, os projetos oficiais acabaram também resultando na valorização e na promoção da memória dos escravagistas, contexto no qual se insere a reconstrução da memória de Francisco Félix de Souza.

O estudo da vida e a carreira de Francisco Félix de Souza oferecem vários elementos que permitem melhor entender as memórias plurais da escravidão existentes no Benim contemporâneo. Apesar de algumas vezes convergirem, essas múltiplas memórias muitas vezes apresentam elementos dissonantes. No Benim contemporâneo, a memória pública visível nos discursos dos descendentes de escravos retornados e de mercadores escravos contém algumas particularidades, pois estes indivíduos não viveram a experiência de seus ancestrais. Para examinar essas memórias é necessário lidar com mediadores já que as testemunhas dos eventos não existem mais. Tendo como ponto de partida essa premissa, Marianne Hirsch desenvolveu a noção de pós-memória como sendo caracterizada "pela experiência daqueles que cresceram dominados por narrativas que precederam seu nascimento, cujas próprias histórias são evacuadas em benefício das histórias das gerações precedentes que foram definidas por eventos traumáticos que não podem ser nem entendidos nem recriados". ${ }^{6}$ Nesse contexto onde a memória é mediada, a noção de patrimônio material ou imaterial é inevitável, porque o patrimônio é uma herança que participa ativamente da transmissão da identidade. ${ }^{7}$ Para os herdeiros da escravidão -

\footnotetext{
${ }^{6}$ Marianne Hirsch, Family Frames, Photography Narrative and Postmemory, Cambridge, Harvard University Press, 1997, p. 22.

${ }^{7}$ Bogumil Jewsiewicki, "Patrimonialiser les mémoires pour accorder à la souffrance la reconnaissance qu'elle mérite", in Bogumil Jewsiewicki e Vincent Auzas, org., Traumatisme collectif pour patrimoine: Regards croisés sur un mouvement transnational, Quebec, Presses de l'Université Laval, 2008, p. 7.
} 
aqueles que se reclamam descendentes diretos ou indiretos de escravos ou que deles herdaram uma posição de marginalidade e de exclusão - a memória da escravidão é marcada por rupturas e lacunas, enquanto entre os descendentes dos escravagistas (senhores, mercadores de escravos e outros colaboradores) a memória é caracterizada sobretudo pela continuidade. No entanto, como nota Hirsch, entre estes dois grupos, o trabalho de pós-memória se caracteriza pela herança familiar e pela transmissão do trauma cultural. Ao mesmo tempo, embora os descendentes das vítimas, dos sobreviventes e dos autores dos crimes experimentem diferentes experiências em relação com a pós-memória, esse tipo de memória não precisa se restringir ao círculo familiar ou a um grupo que partilha as mesmas marcas étnicas ou nacionais, mas também pode ser disponibilizado através de formas particulares de identificação, adoção ou projeção. ${ }^{8}$ As famílias de mercadores de escravos vindos das Américas ou da Europa que se estabeleceram na costa da África Ocidental durante o período do comércio atlântico de escravos foram capazes de preservar seus laços com as cidades onde seus ancestrais se estabeleceram enquanto também preservaram ligações com o outro lado do Atlântico. Esses laços preservados e a riqueza que essas famílias acumularam durante o período do tráfico de escravos permitiram-lhes perpetuar seus bens pessoais e familiares, tais como casas, mobília, objetos e até mesmo fotografias. A estabilidade de suas posições de elite na sociedade local ajudou-os a preservar práticas culturais e religiosas associadas com suas comunidades portuguesas e/ou brasileiras de origem, ao mesmo tempo em que incorporavam a essas práticas costumes africanos locais. Essa profunda identidade sul-atlântica, grandemente baseada em tradições luso-brasileiras, associando catolicismo e paternalismo, é sólida mas ao mesmo tempo flexível e mestiça, devido a sua abertura às trocas recíprocas. ${ }^{9}$

\section{A comunidade afro-luso-brasileira de Ajudá}

Em 1721, os Portugueses fundaram em Ajudá o forte São João Batista da Ajuda. Em 1727, o reino do Daomé conquistou o reino de Hueda e se apoderou de Ajudá, ganhando assim acesso à costa. Durante o período do

\footnotetext{
${ }^{8}$ Marianne Hirsch, "Surviving Images: Holocaust Photographs and the Work of Postmemory", in Barbie Zelizer, org., Visual Culture and the Holocaust, London, The Atalone Press, 2001, p. 220.

${ }^{9}$ Gilberto Freyre foi um dos primeiros estudiosos a insistir nos elementos particulares da colonização portuguesa no Atlântico Sul. Gilberto Freyre, Casa-Grande छ̇ Senæala, São Paulo, Global Editora, 2003 [1933].
} 
tráfico atlântico de escravos, Ajudá se tornou o segundo porto africano mais importante depois de Luanda. ${ }^{10}$

Como resultado da repressão da revolta dos Malês de 1835 na Bahia, dezenas de africanos libertos foram deportados para a África Ocidental, gerando assim um significativo movimento de retorno à África. Embora não existam estatísticas precisas, calcula-se que entre 3 mil e 8 mil indivíduos tenham retornado ao Golfo do Benim nos meses que seguiram o final da revolta, movimento que se expandiu até o final do século XIX. Na costa da África Ocidental, esses homens, mulheres e crianças se estabeleceram nas cidades costeiras, onde hoje se encontram a República do Benim (Popo Pequeno, Popo Grande, Agouê, Ajudá, Cotonou e Porto Novo) e a atual Nigéria (Badagry e Lagos). Juntaram-se então aos mercadores de escravos portugueses e brasileiros estabelecidos na região desde o século XVIII, dando origem à comunidade Agudá. Em Ajudá, Francisco Félix de Souza apoiou os ex-escravos retornados, ajudando-os a se estabelecer em vários bairros da cidade, como Maro, Brasil, Quénum, Zomaï e Boya. ${ }^{11}$

Hoje em dia, a comunidade Agudá representa de cinco a dez por cento da população do Benim. ${ }^{12}$ No entanto, é preciso enfatizar que essa comunidade não é homogênea, já que entre seus membros encontram-se não somente descendentes de antigos escravos retornados, mas também descendentes de mercadores de escravos brasileiros e portugueses e os descendentes dos escravos mantidos pelos dois grupos anteriores, que foram por eles assimilados. Esses descendentes de assimilados possuem sobrenomes portugueses que seus ancestrais herdaram de seus antigos senhores brasileiros e portugueses, com quem eles passaram a compartilhar certos costumes e elementos da cultura brasileira. ${ }^{13}$ Os membros da comunidade afro-luso-brasileira são católicos, mas também havia entre os retornados muçulmanos e adeptos de outras religiões como o culto dos orixás e o vodun. ${ }^{14}$ Ao mesmo tempo, os retornados que

${ }^{10}$ Law, Ouidah, The Social History of a West African Slaving Port, 1727-1892, p. 2 e Paul E. Lovejoy, "The Context of Enslavement in West Africa: Ahmad Bãbã and the Ethics of Slavery", in Jane Landers e Barry M. Robinson, org., Slaves, Subjects and Subversives: Blacks in Colonial Latin America, Albuquerque, University of New Mexico Press, 2007, p. 25.

${ }^{11}$ Law, Ouidah, The Social History of a West African Slaving Port, 1727-1892, p. 181.

${ }^{12}$ A atual população do Benim é de 8.294.941 habitantes.

${ }^{13}$ Milton Guran, Agudás: Os "Brasileiros" do Benim, Rio de Janeiro, Editora Nova Fronteira, 1999 , p. 88.

${ }^{14}$ Júlio Santana Braga, “Notas sobre o 'Quartier Brésil' no Daomé”, Afro-Ásia, 1968, p. 189; Guran, Agudás: Os "Brasileiros" do Benim, p. 15; Manuela Carneiro da Cunha, Negros, estrangeiros: os escravos libertos e sua volta à África, São Paulo, Brasiliense, 1985, p. 189. 
haviam nascido na África pertenciam a diferentes grupos étnicos e falavam diferentes línguas maternas, principalmente o iorubá, mas também outras línguas do grupo Gbe.

Apesar desses traços distintivos, todos os retornados tinham um passado comum marcado pela escravização e pelas experiências vividas no Brasil. Diferentemente da população local, eles haviam sido batizados e tinham sobrenomes portugueses como Silva, Reis, Assunção, Almeida, Santos, Cruz, Paraíso, Oliveira e Souza, se vestiam segundo os códigos ocidentais e tinham costumes de "branco". Nos primeiros tempos, as famílias Agudás optavam pela endogamia, casando quase sempre com membros da própria comunidade, para assim preservar sua coesão. Os retornados também trouxeram do Brasil uma culinária particular, que incluía pratos como feijoada, cozido e abará, um bolinho parecido com o acarajé. A comunidade também desenvolveu uma arquitetura doméstica particular inspirada na arquitetura colonial luso-brasileira. Em Benim, a construção dessas residências "brasileiras", que tipicamente possuem dois andares e uma varanda, exerceu uma influência considerável entre a população local, que passou a reproduzir e adotar alguns elementos decorativos do novo estilo arquitetônico. ${ }^{15}$

Estabelecidos no Golfo do Benim, vários dos antigos retornados se tornaram por sua vez mercadores de escravos. Mesmo não tendo acumulado grandes fortunas, como outros mercadores de escravos da região, alguns retornados se tornaram prósperos. No ano de 1850, como observou Manuela Carneiro da Cunha, vários retornados se encontravam ativos no comércio de escravos em cidades como Ajudá, Agoué e Porto Novo. ${ }^{16}$

A população local percebia a comunidade Agudá como um grupo mais educado e "civilizado" devido aos seus costumes diferentes. Essa ocidentalização também era percebida como assimilação e como negação de suas origens africanas, sendo essa aparente "superioridade" vista negativamente pela população local. Como ser um Agudá significava pertencer a uma burguesia moderna, algumas famílias locais procuraram assim seguir e até mesmo imitar o modo de vida Agudá, às vezes até adotando sobrenomes portugueses.

Em 1892, as regiões que constituíam o reino do Daomé e o reino de Porto Novo foram conquistadas e passaram assim a fazer parte da colônia francesa do Daomé. Com o final do tráfico atlântico de escravos a importância

${ }^{15}$ Alain Sinou, "La Valorisation du patrimoine architectural et urbain: l'exemple de la ville de Ouidah au Bénin”, Cahiers des Sciences Humaines, vol. 29, n. 1, 1993, p. 36.

${ }^{16}$ Cunha, Negros, estrangeiros: os escravos libertos e sua volta à África, p. 109. 
econômica e política da comunidade Agudá já havia começado a diminuir. No entanto, os membros da comunidade foram capazes de forjar um novo lugar na sociedade colonial emergente. Ocidentalizados, aportuguesados e brasilianizados, muitos Agudás percebiam a presença européia como sendo vantajosa. ${ }^{17}$ Muitos retornados e descendentes de retornados continuaram a exercer profissões que trouxeram consigo do Brasil (carpinteiros, alfaiates, pedreiros), enquanto outros passaram a ocupar postos administrativos (como escrivães, intérpretes, negociantes). ${ }^{18}$ Tornaram-se assim colaboradores do regime francês e em troca receberam favores, conquistando e consolidando uma posição privilegiada na sociedade colonial. As páginas do Journal officiel de la colonie du Dahomey não só identificam nomes de vários membros da comunidade Agudá que tiveram postos administrativos durante o período colonial, mas também revelam o quanto alguns membros da comunidade Agudá endossaram o regime colonial. ${ }^{19}$

Depois da independência do Daomé em agosto de 1960, a comunidade Agudá perdeu dramaticamente sua antiga influência política. Com a emergência do sentimento nacional, os Agudás foram vistos como sendo aqueles que tinham colaborado com o regime francês. Quando o general Mathieu Kérékou se tornou presidente do país em 1972 e estabeleceu em seguida uma ditadura marxista-leninista, as mudanças econômicas e sociais introduzidas tiveram um impacto negativo sobre as famílias Agudás mais ricas. Aqueles que se opuseram ao novo regime, tais como Francisca Patterson (nascida Medeiros), foram presos, ${ }^{20}$ enquanto outros empresários, como Urbain-Karim-Elisio da Silva, afirmam ter considerado a possibilidade de deixar o país, mesmo se este último mais tarde tenha se tornado um dos braços direitos do presidente Kérékou. $^{21}$

Em 1990, vários membros distintos da comunidade Agudá, como monsenhor Isidore de Souza (1934-1999), arcebispo de Cotonou, participaram ativamente na organização da Conferência Nacional das Forças Vivas da Nação, que estabeleceu os meios para a transição democrática e preparou a

\footnotetext{
${ }^{17}$ Catherine Coquery-Vidrovitch, L'Afrique occidentale au temps des Français: colonisateurs et colonisés (c.1860-1969), Paris, La Découverte, 1992, p. 373.

${ }^{18}$ Bako-Arifari, "La mémoire de la traite négrière dans le débat politique au Bénin dans les années 1990”, p. 222.

${ }^{19}$ Araujo, "Mémoires de l'esclavage et de la traite des esclaves dans l'Atlantique Sud", p. 135-136.

${ }^{20}$ Entrevista com Francisca Patterson (nascida Medeiros), Porto Novo, 2 de agosto de 2005.

${ }^{21}$ Entrevista com Urbain-Karim-Elisio da Silva, Porto Novo, 22 de julho de 2005.
} 
agenda para as eleições do país. ${ }^{22}$ Com o final da ditadura e o desenvolvimento de projetos de patrimonialização da escravidão e de promoção das culturas e das religiões derivadas do vodun, alguns membros da comunidade Agudá começaram a recuperar prestígio e visibilidade na cena política do país. Esse foi o caso da família Vieyra, cujo ancestral Sabino Vieyra era um antigo escravo que retornou do Rio de Janeiro. Rosine Vieyra Soglo, a esposa do presidente Nicéphore Soglo, foi eleita deputada nos anos 1990 e participou do governo de seu marido, enquanto durante o mesmo período seu irmão Désiré Vieyra foi nomeado ministro no mesmo governo.

Durante os anos 1990, após a Conferência Nacional, a atenção internacional recebida pelo Benim, devido aos projetos de promoção do vodun e das culturas africanas e de recuperação da memória da escravidão e do comércio atlântico de escravos, teve sem dúvida papel importante na criação de oportunidades para alguns membros da comunidade Agudá de recuperar certo prestígio politico. Ao mesmo tempo em que reivindicavam uma identidade "brasileira", os Agudás foram incentivados a falar publicamente sobre o passado escravo, assunto que antes era geralmente evitado. No entanto, enfatizar o passado escravo também tinha por consequência ressaltar os elementos que diferenciavam os membros da comunidade que são descendentes de escravos daqueles que são descendentes de mercadores de escravos. Nessa perspectiva, conceber uma identidade brasileira comum se tornava às vezes uma tarefa complicada, porque significava apagar as múltiplas memórias da escravidão. ${ }^{23}$

Os Agudás passaram então a promover sua história e seu patrimônio, aderindo assim ao movimento de patrimonialização. Hoje, os Agudás continuam a enfatizar a centralidade de seus laços com o Brasil, mas atualmente essa promoção não está isenta de intenções políticas. Turistas norte-americanos e autoridades brasileiras de passagem por Porto Novo ou Ajudá visitam com frequência as famílias Agudás mais prestigiosas, inclusive aquelas que são descendentes de mercadores de escravos. Para muitos Agudás, o Brasil é hoje uma potência emergente, ao mesmo tempo distinta do antigo colonizador francês. O Brasil representa não somente um vínculo com o passado, mas também uma promessa de futuro, um horizonte de esperança.

\section{Francisco Félix de Souza}

22 Tall, "De la démocratie et des cultes voduns au Bénin".

${ }^{23}$ Bako-Arifari, "La mémoire de la traite négrière dans le débat politique au Bénin dans les années 1990”, p. 223. 
Francisco Félix de Souza é considerado o fundador da comunidade Agudá do Benim. O mercador de escravos teria nascido em 1754 em Salvador, Bahia, ${ }^{24}$ mas pouco se sabe sobre o período anterior ao seu estabelecimento em Ajudá. A tradição familiar descreve de Souza como um brasileiro típico. Segundo a tradição, ele era branco, tinha ancestrais portugueses do lado paterno e sua mãe seria uma indígena da Amazônia. Mesmo sendo a Região Amazônica um território ainda pouco conhecido no final do século XVIII e começo do século XIX, a floresta aparece com frequência nos discursos dos membros da família, como símbolo de um Brasil imaginário, rico em recursos naturais. Simone de Souza, uma historiadora e genealogista local que faz parte da família, por exemplo, descreve Francisco Félix de Souza como membro de uma família de origem composta principalmente por militares e administradores. Segundo ela, o mercador brasileiro era descendente da oitava geração do português Tomé de Souza (1503-1573 ou 1579), o primeiro governador-geral do Brasil e fundador da cidade de Salvador. ${ }^{25}$ Hoje em dia, essa versão foi levemente modificada pela família e Francisco Félix de Souza é identificado como sendo neto de Tomé de Souza, mesmo se esta hipótese seja incompatível com o fato de que o governador-geral faleceu quase duzentos anos antes do nascimento do mercador de escravos. ${ }^{26}$ Essas sucessivas revisões da biografia de Félix de Souza são tentativas de preencher a falta de informação sobre os anos de juventude do mercador de escravos brasileiro, contribuindo assim para a reconstrução de sua memória.

De Souza teria vindo à costa da África Ocidental pela primeira vez em $1792 .{ }^{27}$ Ele teria passado três anos na região do Golfo do Benim, retornado ao Brasil e depois disso teria voltado a se estabelecer definitivamente na África por volta de 1800. Em Ajudá, ele teria servido como governador do forte português São João Batista da Ajuda, posto deixado vago depois da morte de seu irmão Jacinto José de Souza. ${ }^{28}$ Alguns anos mais tarde, ele abandonou o

${ }^{24}$ Costa e Silva, Francisco Félix de Souza: mercador de escravos, p. 12; Law, "A carreira de Francisco Félix de Souza na África Ocidental (1800-1849)", p. 5.

${ }^{25}$ Simone de Souza, La Famille de Souza du Bénin-Togo, Cotonou, Les éditions du Bénin, 1992.

26 "Discours de bienvenue du porte-parole de son Excellence Mito Honoré Feliciano Julião de Souza, Chacha 8 à la délégation de l'Université de Rutgers (État du New Jersey)", Ouidah, 24 de julho de 2005.

${ }^{27}$ Law, "A carreira de Francisco Félix de Souza na África Ocidental (1800-1849)", p. 13-14; Law, Ouidah, The Social History of a West African Slaving Port, 1727-1892, p. 165 e Costa e Silva, Francisco Félix de Sousa: mercador de escravos, p. 12.

${ }^{28}$ Law, Ouidah, The Social History of a West African Slaving Port, 1727-1892, p. 165. 
posto no forte e se tornou mercador de escravos por conta própria. ${ }^{29} \mathrm{De}$ acordo com os viajantes europeus que encontraram de Souza, ao chegar ao Golfo do Benim ele era tão pobre que era obrigado a roubar os búzios das oferendas dos altares dos templos vodun. ${ }^{30}$

Em Ajudá, de Souza entrou em conflito com Adandozan (r. 1797-1818), rei do Daomé, provavelmente devido a uma dívida relativa ao comércio de escravos. De Souza teria ido então até Abomé, capital do Daomé ter com o rei, mas este último, se sentindo desafiado, enviou-o à prisão. ${ }^{31}$ Segundo a tradição, o rei teria punido de Souza, ordenando aos guardas da prisão mergulhá-lo em uma jarra com índigo com o objetivo de escurecer sua pele, operação que teria sido repetida várias vezes durante várias semanas. ${ }^{32} \mathrm{Na}$ prisão, de Souza teria encontrado o príncipe Gakpé, um meio-irmão de Adandozan e um dos filhos do rei Agonglo (r. 1789-1797), assassinado em 1797. Gakpé teria visitado de Souza na prisão e os dois teriam decidido reunir esforços para lutar contra Adandozan. Para confirmar a aliança realizada, eles teriam feito um pacto de sangue, prática bastante conhecida e utilizada no antigo reino do Daomé. ${ }^{33}$

De Souza conseguiu escapar da prisão e foi se estabelecer em Popo Pequeno (atual Anécho). De lá, ele forneceu ao príncipe Gakpé víveres e armas, permitindo a ele preparar o golpe de estado. ${ }^{34}$ Adandozan foi deposto em 1818 e o príncipe Gakpé se tornou rei Guezo (r. 1818-1850). O novo rei então convidou de Souza a se estabelecer em Ajudá e tomar conta das relações comerciais do reino. De Souza era conhecido como "chachá", apelido que ele teria recebido quando escapava da prisão e que acabou se tornando um título honorífico. Segundo a tradição oral, os guardas palacianos teriam perguntado aos homens que ajudaram de Souza a fugir o que eles estavam carregando e estes responderam: "um chachá", que significaria "esteira". ${ }^{35}$ No entanto, esta versão parece pouco provável, pois em fon, língua falada na capital Abomé, a palavra esteira é zàn. Em língua fon, a palavra chachá (cacà) significa "feito

${ }^{29}$ Pierre Verger, Flux et reflux de la traite des nègres entre le Golfe de Bénin et Bahia de Todos os Santos, du XVIIe au XIXe siècle, Paris, Mouton, 1969, p. 638; Law, "A carreira de Francisco Félix de Souza na África Ocidental (1800-1849)", p. 16; Law, Ouidah, The Social History of a West African Slaving Port, 1727-1892, p. 165.

${ }^{30}$ Costa e Silva, Francisco Félix de Sousa: mercador de escravos, p. 14; Law, "A carreira de Francisco Félix de Souza na África Ocidental (1800-1849)”, p. 11.

${ }^{31}$ Paul Hazoumé, Le Pacte de Sang au Dahomey, Paris, Institut d'ethnologie, 1956, p. 28.

${ }^{32}$ Hazoumé, Le Pacte de Sang au Dahomey, p. 29.

${ }^{33}$ Hazoumé, Le Pacte de Sang au Dahomey, p. 29.

${ }^{34}$ Costa e Silva, Francisco Félix de Souza: mercador de escravos, p. 86.

${ }^{35}$ Costa e Silva, Francisco Félix de Souza: mercador de escravos, p. 89. 
rapidamente". ${ }^{36} \mathrm{O}$ apelido de Félix de Souza poderia ser então uma adaptação de “já já”, expressão em língua portuguesa usada com frequência por de Souza. A palavra chachá se tornou mais tarde um título hereditário atribuído ao mais alto representante da família de Souza. Depois da morte de Félix de Souza, o primeiro chachá, o rei do Daomé se encarregava de nomear os seus sucessores. A partir do começo da colonização francesa no final do século XIX e a supressão da monarquia daomeana, a família de Souza tomou em mãos a nomeação dos futuros chachás. Nessa época, a função do chachá também perdeu sua importância e a família já não tinha mais o poder político de outrora, o que aumentou ainda mais suas divisões internas. As dificuldades encontradas para eleger o mais alto representante da família levaram a longos períodos de vacância no cargo.

Comumente o cargo ocupado por Francisco Félix de Souza é associado com o posto de vice-rei. ${ }^{37}$ No entanto, nos últimos anos, a tradição local que geralmente designa de Souza como chefe dos brancos foi questionada por Robin Law, que insiste sobre o fato de que este cargo, também conhecido como o posto de yovogan, sempre foi preenchido por um nativo. ${ }^{38}$ Essa superestimação do status de Félix de Souza pode ser atribuída em parte aos viajantes britânicos, que em seus relatos descreveram o mercador brasileiro como um homem rico e poderoso. No entanto, esses mesmos relatos de viagem indicam que quando os viajantes europeus chegavam a Ajudá, iam ter primeiramente com o yovogan, e somente após encontrar o chefe dos brancos iam visitar o chachá. Na realidade, de Souza era um chefe local ou cabeceira. ${ }^{39}$ Apesar disso, se o termo vice-rei não descreve com precisão a função ocupada por de Souza, Alberto da Costa e Silva observou com propriedade que, num contexto de autocracia, "ser o agente comercial do rei era, contudo, uma função política". ${ }^{40}$ A importância da posição ocupada por de Souza é claramente enfatizada pelo

\footnotetext{
${ }^{36}$ Basilio Segurola e Jean Rassinoux, Dictionnaire Fon-Français, Madrid, Société des Missions Africaines, 2000.

${ }^{37}$ A informação segundo a qual Francisco Félix de Souza teria sido nomeado vice-rei foi disseminada principalmente através do romance de Bruce Chatwin, The Viceroy of Ouidah. Law, "A carreira de Francisco Félix de Souza na África Ocidental (1800-1849)", p. 18; Law, Ouidah, The Social History of a West African Slaving Port, 1727-1892, p. 167-168. Autores como Guran (Agudás: os "Brasileiros" do Benim, p. 22) também reproduzem a afirmação segundo a qual de Souza era vice-rei.

${ }^{38}$ Após 1823, um homem cujo sobrenome era Dagba ocupou este posto.

${ }^{39}$ Law, Ouidah, The Social History of a West African Slaving Port, 1727-1892, p. 168.

${ }^{40}$ Costa e Silva, Francisco Félix de Souza: mercador de escravos, p. 90.
} 
próprio rei Guezo em uma carta enviada ao rei Dom João Carlos de Bragança, juntamente com a embaixada que foi ao Brasil em 1818:

"depois que tomei conta do meu reino, quem tem ajudado ao meu povo hé o dito Francisco Felis de Souza, porcurando navios para o meu porto tanto portuguezes como as mais nasçoens de sorte que entreguei ao Francisco Felis de Souza todo o domínio que tinha com os brancos que vinha e vem a fazerem negocio, pelo dito ser capaz e todo os navios o estimarem. Honrado Rey, não tenho nada que vos poça mandar por sinal de Amigo Senão duas Molecas e hum Pano feito numa fabrica e peço a V. Magestade queira ceitar os ceos o queira goardar por muntos adelatados anos. Sou Seu Irmão e Amigo. Rey DAgomé”. ${ }^{41}$

Segundo Pierre Verger, os embaixadores desembarcaram na Bahia, onde ficaram mais de um ano a esperar por transporte para viajar até o Rio de Janeiro, de onde voltaram para o Daomé sem terem conseguido chegar até a corte. ${ }^{42} \mathrm{O}$ conteúdo da carta não deixa dúvidas sobre o quanto de Souza era considerado o braço direito do rei Guezo e como ele era percebido como um ator de grande importância política tanto pela sociedade daomeana como pelos visitantes europeus.

O período do reinado do rei Guezo e a indicação de Francisco Félix de Souza para o cargo de seu agente comercial coincidiram com o lento declínio do comércio atlântico de escravos e a transição para o comércio legítimo do azeite-de-dendê. Até 1830, de Souza foi um mercador bastante próspero que possuía vários navios negreiros. ${ }^{43}$ No entanto, em torno de 1840 , suas atividades tinham decaído consideravelmente, de um lado devido a sua idade avançada e de outro devido às medidas repressivas contra o comércio de escravos impostas pela Inglaterra, que com seu esquadrão naval havia nessa época confiscado 22 navios que lhe pertenciam. ${ }^{44}$ No momento da sua morte em 1849 , de Souza tinha dívidas consideráveis junto ao rei Guezo e também com mercadores brasileiros e cubanos. Nesse sentido, segundo vários membros da família de

\footnotetext{
${ }^{41}$ Instituto Histórico e Geográfico Brasileiro (IHGB), DL 137.62, Doc. 6, Lata 137, Pasta 62, Carta do Rei Guezo ao Rei Dom João Carlos de Bragança, fols. 1-2, 2v. Transcrição da autora. A carta não é datada e embora a pasta indique que as cartas arquivadas vão até o ano de 1811, esta carta é posterior, pois Guezo subiu ao trono em 1818.

${ }^{42}$ Pierre Verger, Os Libertos: Sete Caminhos na Liberdade de Escravos da Bahia no Século XIX, Salvador, Corrupio, 1992, p. 70.

${ }^{43}$ Law, "A carreira de Francisco Félix de Souza na África Ocidental (1800-1849)”, p. 23.

${ }^{44}$ John Duncan, Travels in Western Africa in 1845 \& 1846: comprising a journey from Whydah, through the kingdom of Dahomey, to Adofoodia in the interior, London, Frank Cass, 1968 [1847], vol. 1, p. 204; Law, "A carreira de Francisco Félix de Souza na África Ocidental (1800-1849)", p. 28 .
} 
Souza, após seu falecimento, o rei Guezo enviou seus agentes até a residência do mercador em Ajudá com o objetivo de confiscar seus bens.

\section{Um memorial em homenagem ao mercador de escravos}

Singbomey é o nome do conjunto residencial da família de Souza, localizado no bairro Brasil, em Ajudá. Durante a primeira metade do século XIX, foi nesse bairro que de Souza viveu e também foi nele que algumas famílias de antigos escravos retornados se estabeleceram com o apoio do mercador. No fundo do grande pátio interno do conjunto residencial se encontram duas grandes residências de um único andar, bastante sóbrias, pintadas em cor vermelha-alaranjada, inspiradas na arquitetura doméstica brasileira dos séculos XVIII e XIX. Dentro das duas casas, que faziam parte da antiga residência de Francisco Félix de Souza, se encontra o memorial em sua homenagem. Apesar de o memorial existir há vários anos, ele só se tornou acessível ao público a partir dos anos 1990, quando Honoré Feliciano Julião de Souza foi nomeado como oitavo chachá.

Quando visitei pela primeira vez o memorial em companhia de Christian de Souza e David de Souza, ${ }^{45}$ jovens membros da família bastante próximos ao oitavo chachá, existia uma intenção clara de reabilitar a memória de seu ancestral, apresentando-o não como mercador de escravos, mas como grande empresário. ${ }^{46}$ Nessa ocasião os dois membros da família enfatizaram os laços da família com o Brasil e justificaram as atividades de Francisco Félix de Souza, insistindo sobre o fato de que naqueles tempos o comércio de escravos era uma atividade legal. Segundo a família, de Souza contribuiu para o desenvolvimento da África, introduzindo novos produtos e novas culturas na região, tal como o dendezeiro.

Os vários relatos que coletei durante minhas entrevistas indicam que a história da família de Francisco Félix de Souza inclui vários episódios de traição recíproca e também situações de colaboração estreita com os europeus em troca de poder político. A existência de diferentes grupos de interesse dentro da família criou frequentemente conflitos sérios; alguns desses episódios envolvendo inclusive mortes suspeitas, provavelmente resultado de

\footnotetext{
${ }^{45}$ Christian de Souza, durante a visita ao memorial de Francisco Félix de Souza, Singbomey (Ajudá), 19 de junho de 2005.

${ }^{46}$ Ana Lucia Araujo, "Renouer avec le passé brésilien: la reconstruction du patrimoine post-traumatique ches la famille De Souza au Bénin”, in Jewsiewicki e Auzas, org., Traumatisme collectif pour patrimoine, p. 305-330.
} 
envenenamento. Os desentendimentos com a família real de Daomé também marcaram profundamente a memória familiar. Ainda hoje, por exemplo, existe a crença de que um casamento entre um de Souza e um fon de Abomé é fadado ao fracasso, tendo como consequência doenças graves e divórcio. Ao ser entrevistada, uma senhora idosa da família, por exemplo, afirmou que sua filha estava em depressão profunda devido a um casamento malsucedido com um fon de Abomé. ${ }^{47}$ Segundo vários relatos que circulam, aqueles que não ouvem as advertências se arrependem mais tarde. Apesar do pacto de sangue entre de Souza e o rei Guezo ter sido proveitoso, o preço pago pela família foi também bastante elevado.

Durante a visita ao memorial, o visitante é confrontado a várias memórias relacionadas não somente com o comércio atlântico de escravos e com a realeza daomeana, mas também com as trocas recíprocas entre o Daomé e o Brasil. Christian de Souza enfatizou o fato de que a história do Daomé insiste sobre a oposição entre o rei Guezo "construtor" e Francisco Félix de Souza "o mercador de escravos". Ao mesmo tempo, durante a visita, Christian de Souza minimizou os conflitos entre seus ancestrais e a realeza do Daomé para acentuar sobretudo a colaboração estabelecida entre eles.

Segundo a família, Francisco Félix de Souza foi quem resgatou $\mathrm{Na}$ Agontimé $^{48}$-uma das esposas do rei Agonglo que é também identificada como rainha-mãe do rei Guezo - da escravidão. Após o assassinato do seu esposo, $\mathrm{Na}$ Agontimé teria sido vendida como escrava e enviada ao Brasil pelo rei Adandozan. Apesar da falta de fontes escritas confirmando este acontecimento, várias divindades dos reis do Daomé estão presentes no vodun praticado na Casa das Minas no estado do Maranhão. ${ }^{49}$ Essas divindades eram pre-existentes ao rei Agonglo. ${ }^{50}$ Segundo a versão largamente aceita por autores como Melville

${ }^{47}$ Entrevista com Marie de Souza (nome fictício) e David de Souza, Cotonou, 23 de julho de 2005.

${ }^{48}$ Edna Bay, Wives of the Leopard: Gender, Politics and Culture in the Kingdom of Dahomey, Charlottesville, VA, University of Virginia Press, 1998, p. 180; Edna Bay, "Protection, Political Exile, and the Atlantic Slave Trade: History and Collective Memory in Dahomey", Slavery $\mathbb{E}^{\circ}$ Abolition, vol. 22, n. 1, 2001, p. 16-18.

${ }^{49}$ Luis Nicolau Pares, "The Jeje in the Tambor de Mina of Maranhão and in the Candomble of Bahia", Slavery \& Abolition, vol. 22, n. 1,2001, p. 91-115.

${ }^{50}$ Pierre Verger, "Le culte des vodoun d'Abomey aurait-il été apporté à Saint Louis de Maranhão par la mère du roi Ghèzo?", Études Dahoméennes, n. 8, 1952, p. 22-23; Edna Bay, "Protection, Political Exile and the Atlantic Slave Trade: History and Collective Memory in Dahomey", in Kristin Mann e Edna G. Bay, org., Rethinking the African Diaspora : The Making of a Black Atlantic World in the Bight of Benin and Brazil, London, Frank Cass, 2001, p. 57; Judith Gleason, Agotime: Her Legend, New York, Grossman, 1970. 
Herskovits e Pierre Verger, foi Na Agontimé quem introduziu o vodun de Abomé no Brasil. ${ }^{51}$ Supostamente tendo liberado a mãe do rei, Francisco Félix de Souza transformou então a ruptura provocada pelo comércio atlântico de escravos em uma ligação frutífera com o Brasil.

Apesar de a tradição afirmar que de Souza foi quem salvou a mãe do rei Guezo, nenhum documento comprova que o mercador de escravos brasileiro realmente viajou para o Brasil para procurar Na Agontimé. Em 1821, apesar de ter obtido um passaporte lhe permitindo viajar ao Brasil no navio Príncipe de Guiné, que alguns anos mais tarde foi apreendido pela marinha britânica, não há registros que esta viagem tenha se realizado. ${ }^{52}$ No entanto, esse fato dificilmente explica por que ele não teria tentado viajar mais tarde. Existiriam então duas possibilidades: o rei Guezo teria proibido de Souza de deixar o Daomé, ou o mercador de escravos teve problemas de ordem legal que não lhe permitiam entrar no Brasil. De fato, o rei Guezo provavelmente enviou à Bahia um dos empregados de Francisco Félix de Souza, chamado Antônio Dossoo-Yavoo (1762-1887), ${ }^{53}$ que também havia ajudado de Souza a escapar da prisão. ${ }^{54}$

Christian de Souza e David de Souza descrevem seu ancestral como um homem viril. Segundo eles, Francisco Félix de Souza teve 201 filhos: 106 filhas e 95 filhos. Eles não atribuem essa grande progenitura à riqueza que lhe permitia ter várias mulheres e várias escravas, mas sobretudo a sua extraordinária virilidade e força física. Na realidade, devido a sua reputação de homem rico e poderoso, muitas pessoas em Ajudá reivindicam ser descendentes de Francisco Félix de Souza. Força física e qualidades sedutoras são traços atribuídos ao mercador de escravos não somente no discurso familiar, mas também em obras de ficção como o romance The Viceroy of Ouidah (1980) de Bruce Chatwin e no filme Cobra Verde (1987), uma adaptação do romance por Werner Herzog para o cinema. No filme, Francisco Félix de Souza aterroriza os homens e é capaz de seduzir belas e jovens mulheres sem mesmo precisar dizer uma palavra.

${ }^{51}$ Pierre Verger, Os Libertos: Sete Caminhos na Liberdade de Escravos da Bahia no Século XIX, Salvador, Corrupio, 1992, p. 71-72.

${ }^{52}$ Law, Ouidah, The Social History of a West African Slaving Port, 1727-1892, p. 166.

${ }^{53} \mathrm{O}$ nome e as datas de nascimento e de falecimento se encontram no túmulo de DossooYavoo em Ajudá, cuja fotografia feita por Pierre Verger se encontra hoje na Fundação Pierre Verger em Salvador, BA. Agradeço a Ângela Lühning, Alex Baradel e Roberta Rodrigues por me darem acesso a uma cópia dessa fotografia.

${ }^{54}$ Law, Ouidah, The Social History of a West African Slaving Port, 1727-1892, p. 177; Bay, Wives of the Leopard: Gender, Politics and Culture in the Kingdom of Dahomey, p. 179. 


\section{Oancestral com poderes curativos}

Dentro do memorial, o antigo quarto de Francisco Félix de Souza continua até hoje intacto. Dentro dele, se encontram não somente sua cama original, feita de jacarandá e trazida do Brasil e arrumada como se ele estivesse ainda vivo, mas também seu túmulo. O quarto reforça a idéia de que de Souza se mantém presente entre os membros da família. Segundo David de Souza, quando seu ancestral morreu, o rei do Daomé "enviou uma dúzia de escravos, uma dúzia de homens para serem enterrados vivos junto com ele, mas seus filhos disseram 'é fora de cogitação, nós não apoiamos esse tipo de coisa',... e os homens foram então liberados". ${ }^{55}$ De fato, apesar da alegada oposição da família, de Souza recebeu todas as honras de um funeral de um grande chefe daomeano: quatro indivíduos foram sacrificados, dois na praia e dois sobre seu túmulo. ${ }^{56} \mathrm{O}$ relato da oposição familiar ao sacrifício busca apresentar uma imagem ocidentalizada e humana da família de Souza, que rejeitaria as práticas religiosas locais e também a crueldade praticada contra os escravos. Segundo o relato, os escravos teriam sido não apenas poupados do sacrifício, como também liberados.

A família de Souza é tida como católica, mas quando Francisco Félix de Souza se estabeleceu em Ajudá, o rei Guezo ordenou a instalação na cidade de vários templos vodun para protegê-lo. Perto do túmulo de Francisco Félix de Souza existe uma grande jarra de cerâmica que segundo os membros da família foi trazida do Brasil. Essa jarra contém a água usada nos rituais de libação para curar os membros da família vivendo algum tipo de dificuldade. ${ }^{57}$ Nesse contexto, o ancestral se tornou um tipo de vodun, uma divindade que é capaz de curar. Na religião vodun, o espírito ou divindade deve ocupar um lugar preciso no espaço físico. A presença de Francisco Félix de Souza em seu antigo quarto é assegurada por seu túmulo, enquanto a água conservada na jarra de barro produz a cura. Esse quarto se tornou um símbolo maior dos laços originais da família com o Brasil e também da influência política ainda exercida pela família sobre toda a comunidade Agudá e outros grupos presentes em Ajudá. A santificação de Francisco Félix de Souza ajuda a aumentar

\footnotetext{
${ }^{55}$ Entrevista filmada com Christian de Souza e David de Souza, durante a visita ao memorial de Francisco Félix de Souza, Singbomey (Ajudá), 19 de junho de 2005.

${ }^{56}$ Law, Ouidah, The Social History of a West African Slaving Port, 1727-1892, p. 215.

${ }^{57}$ Entrevista filmada com Christian de Souza e David de Souza, durante a visita ao memorial de Francisco Félix de Souza, Singbomey (Ajudá), 19 de junho de 2005.
} 
a autoridade da família, que, além do terreno econômico e político, ocupa também a arena religiosa.

Como outras famílias de Ajudá, os de Souza possuíam escravos comprados das regiões vizinhas e empregados na economia local, principalmente trabalhando na agricultura ou nos serviços domésticos. Aqueles que eram iniciados em diferentes cultos tais como o Egungun e o Zangbeto, ou ainda em práticas divinatórias como o Ifá, exerciam funções religiosas. Por exemplo, o ancestral da família Olougoudou que pertencia à família real de Abeokutá foi trazido para Ajudá em 1830, numa época em que o comércio de escravos na região já era considerado ilegal. Segundo o historiador e professor Émile Olougoudou, seu ancestral se encontrava em um navio que transportava escravos, cujo destino final era as Américas. $\mathrm{O}$ navio entrou em pane enquanto circundava a costa do Golfo do Benim e foi acostar em Ajudá. Segundo Olougoudou, de Souza comprou todos os seiscentos cativos a bordo, "salvando-os" de serem vendidos como escravos nas Américas. ${ }^{58}$

$\mathrm{O}$ relato de Olougoudou sugere que bem longe de ter sido considerado negativamente por seus escravos, muitos tinham grande estima pelo mercador, que era visto como um homem generoso que ajudava os cativos. Essa imagem corresponde à imagem apresentada pelos viajantes britânicos da época. Segundo Frederick Forbes, por exemplo, de Souza tinha valores que diferiam dos das populações indígenas. Entre outros, ele teria se oposto aos sacrifícios humanos. ${ }^{59} \mathrm{~A}$ família de Souza perpetua esse aspecto da reputação do mercador de escravos, como mostra David de Souza:

"Quando os escravos eram trazidos a Ajudá para serem vendidos, algumas famílias reconheciam seus parentes. Eles costumavam pedir ao Chachá de ajudá-los a salvar o cativo que seria vendido e enviado do outro lado do oceano. Nos louvores existentes na família existe uma passagem louvando Dom Francisco Félix de Souza. Nós dizemos, aquele que re-compra o escravo para dar-lhe de volta a sua família, aquele que salva o escravo". ${ }^{60}$

Na realidade, a passagem à qual David de Souza se referia (é plé vi plé nò) significa "ele comprava a mãe e o filho". No entanto, em torno de 1990, quando Honoré Feliciano Julião de Souza foi nomeado como oitavo chachá, ${ }^{58}$ Entrevista com Emile Olougoudou, Ajudá, 24 de julho de 2005.

${ }^{59}$ Frederick E. Forbes, Dahomey and the Dahomans. Being the journals of two missions to the king of Dahomey and residence at his capital in the years 1849 and 1850, London, Frank Cass, 1966 [1851], vol. I, p. 106-108.

${ }^{60}$ David de Souza durante entrevista com Honoré Félicien Julião de Souza (Chachá VIII) e David de Souza, Singbomey, Ajudá, 19 de junho de 2005. 
esta passagem do louvor foi suprimida porque ela era uma referência clara ao comércio de seres humanos. Mesmo se comprar a mãe e seu filho pode ser interpretado como uma tentativa de evitar que membros da família fossem separados, este gesto também pode ser entendido como uma demonstração de quão rico era o mercador brasileiro que podia comprar vários membros da mesma família ao mesmo tempo. A memória de Francisco Félix de Souza é então reconstruída de acordo com valores do tempo presente. O mercador de escravos é representado como sendo um homem preocupado com os direitos humanos e disposto a liberar os escravos. No entanto, parece que essa idéia não é algo assim tão novo. John Duncan escreveu em seu relato de viagem que de Souza era generoso com seus escravos. ${ }^{61}$ Como Robin Law mostrou, alguns viajantes que encontraram de Souza realmente o consideravam como um grande filantropo, "baseado no fato de que ele salvava a vida dos escravos que ele comprava para exportar", consequentemente evitando que esses homens e mulheres fossem sacrificados. ${ }^{62}$

Cerca de cem metros de Singbomey, na estrada em direção à praia, se encontra o templo do Dagoun, o vodun de Francisco Félix de Souza. Apesar de ser católico, o mercador era o único a possuir seu próprio vodun. Segundo a versão mais verossímil sobre a origem do Dagoun, quando o rei Guezo convidou de Souza a se estabelecer em Ajudá, ele lhe deu dois voduns para proteger a cidade; o primeiro foi assentado na entrada da cidade, enquanto o segundo foi colocado na saída da cidade. De Souza também recebeu um terceiro vodun para sua proteção pessoal, o Dagoun. ${ }^{63}$

Hoje em dia, os descendentes dos chefes religiosos enviados a Ajudá, durante o reino do rei Guezo, continuam próximos da família de Souza. ${ }^{64} \mathrm{~A}$ relação entre de Souza e a realeza daomeana nem sempre foi um rio tranquilo e a presença de chefes tradicionais enviados pelo rei do Daomé era parte dessa relação às vezes conturbada. Através dos chefes religiosos, o rei podia controlar as atividades da família de Souza. O atual chachá oitavo conserva sua autoridade sobre os chefes dos cultos tradicionais do bairro Brasil, em Ajudá. Diferentemente dos chefes dos outros templos, o chefe do Dagoun é escolhido pelo Conselho da família de Souza e não pelo líder nacional supremo do vodun.

${ }^{61}$ Duncan, Travels in Western Africa in 1845 \& 1846: comprising a journey from Whydah, through the kingdom of Dahomey, to Adofoodia in the interior, vol. I, p. 114.

${ }^{62}$ Law, "The Atlantic Slave Trade in Local History Writing in Ouidah", p. 274, nota 20.

${ }^{63}$ Guran, Agudás: os "Brasileiros" do Benim, p. 203-204.

${ }^{64}$ Entrevista com Honoré Félicien Julião de Souza (Chachá VIII) e David de Souza, Singbomey, Ajudá, 19 de junho de 2005. 


\section{Memória reabilitada}

O processo de reabilitação da memória de Francisco Félix de Souza começou há mais ou menos quinze anos, quando o chachá oitavo foi nomeado. Hoje em dia, os membros da família discutem abertamente o passado escravagista. Muitos acreditam que de Souza e seus descendentes não podem ser condenados por seu envolvimento com o comércio atlântico de escravos. Eles pensam que não se pode julgar o passado com o olhar do presente e também enfatizam que o comércio de escravos era uma atividade legal no tempo do seu ancestral, mesmo se é sabido que Francisco Félix de Souza e seus filhos continuaram comercializando escravos até os anos 1850, ainda que o embarque de escravos da Baía do Benim para o Brasil tivesse sido decretado ilegal desde 1815 pelos tratados Anglo-Portugueses. Apesar dessas justificativas, para reconstruir a memória do ancestral e ganhar capital político, para os membros da família é necessário atenuar o aspecto do comércio de escravos presente na biografia de Félix de Souza.

Nos últimos anos, provavelmente por causa das repercussões do projeto “Ajudá 92" e do lançamento do projeto "A Rota do Escravo" da UNESCO, discutir o passado do comércio de escravos no Benim não é mais um tabu. No entanto, a escravidão em solo africano e o comércio de escravos muçulmano ficaram fora desse processo de patrimonialização. Ainda hoje, a escravidão em solo africano é percebida como mais humana e benévola e por isso mais aceitável que o comércio atlântico de escravos e que a escravidão nas Américas. No entanto, sabe-se que a intensificação do comércio atlântico de escravos levou a uma transformação na natureza da escravidão na África, que se tornou uma instituição central nas sociedades africanas. ${ }^{65}$

Robin Law sustenta que durante a primeira metade do século XIX, Francisco Félix de Souza não era o único mercador de escravos importante na cidade de Ajudá. Vários outros mercadores de escravos bem-sucedidos estavam estabelecidos na cidade, entre eles Joaquim Teles de Menezes, Juan José Zangronis, Joaquim d'Almeida e Domingos José Martins. Apesar de seu estudo detalhado das redes de comerciantes de escravos de Ajudá, Law negligenciou uma dimensão importante que está relacionada com a memória e não com a história, ou seja, como Francisco Félix de Souza se transformou em uma figura mítica da história de Ajudá e do reino do Daomé, apesar de não

${ }^{65}$ Paul E. Lovejoy, Transformations in Slavery: A History of Slavery in Africa, Cambridge, Cambridge University Press, 2a ed., 2000, p. 21. 
ter sido o único mercador de sucesso da região? Élisée Soumonni e Alberto da Costa e Silva levantaram pontos importantes em relação a essa questão. Eles notaram que de Souza teve um papel central durante a transição para o comércio de azeite-de-dendê, o que contribuiu para consolidar sua reputação. Por muito tempo, ele foi percebido como sendo o "protetor" da comunidade Agudá. Muitos o consideravam mais ocidentalizado e mais "evoluído" do que a população nativa. O exercício desse papel foi possível graças ao posto que lhe foi conferido pelo rei Guezo. Esta posição contribuiu para a construção de sua reputação como um homem generoso, um benfeitor. Apesar de sua origem brasileira, Francisco Félix de Souza se tornou um chefe africano exemplar. ${ }^{66}$

O mito em torno de Francisco Félix de Souza é também baseado nos laços e nas trocas recíprocas entre o Brasil e o Daomé. No quadro da construção de um espaço atlântico meridional, marcado pela ruptura provocada pelo tráfico atlântico de africanos escravizados, de Souza, um homem que se tornou rico comprando escravos, é percebido como o pai generoso que soube preservar uma identidade brasileira maleável e que ajudou os antigos escravos retornados a encontrar sua África natal.

Hoje em dia, a reconstrução da memória de Francisco Félix de Souza é baseada na reconstituição dos laços do Golfo do Benim com o Brasil. A evolução do mito Francisco Félix de Souza também é o resultado do trabalho de historiadores e antropólogos como Pierre Verger, Melville Herskovits e Milton Guran, que privilegiaram o estudo das relações entre a Bahia e o Golfo do Benim, ainda que a maioria dos africanos que vieram para o Brasil trazidos como escravos fossem originários da África Central Ocidental.

Mesmo se de Souza e, mais tarde, também seus descendentes tiveram filhos com mulheres africanas, entre os membros da família ainda persiste uma idéia de autenticidade "biológica". Esta idéia não está associada com pureza racial, mas com certa "brasilianidade", relacionada com hibridização e miscigenação. O mito de Francisco Félix de Souza toma emprestados alguns elementos do mito brasileiro das três raças: a origem da família é baseada no encontro de um homem branco brasileiro de origem portuguesa com uma mulher indígena, cujo filho era um brasileiro genuíno que mais tarde se adaptará perfeitamente ao contexto de uma sociedade da África Ocidental. Como Freyre afirmou, esta identidade brasileira híbrida e suavizada pelo

${ }_{66}$ Élisée Soumonni, Daomé e o mundo atlântico, SEPHIS, South-South Exchange Programme for Research on the History of Development, Centro de Estudos Afro-Asiáticos, n. 2, 2001, p. 13. 
"óleo lúbrico da profunda miscigenação" ${ }^{67}$ permitiu a de Souza construir uma identidade "brasileira" idealizada, que combinada com o catolicismo, o paternalismo, a poligamia e as religiões africanas foi aos poucos incorporando diversas culturas e tradições.

A construção desse mito também foi possível graças a vários fatores políticos e econômicos, que incluem a riqueza do mercador brasileiro e sua posição durante o período de envolvimento do Daomé no comércio atlântico de escravos. Com o passar dos anos, o aspecto religioso do mito teve um papel importante na consolidação da posição de Félix de Souza com um tipo de "vicerei”. De Souza foi responsável pela introdução do catolicismo no Daomé, mas ele também integrou nos seus costumes práticas religiosas locais. Enquanto mais célebre representante da comunidade afro-luso-brasileira do Benim, de Souza gradualmente se africanizou, mas ao mesmo tempo ele passou a representar a idéia de uma identidade mestiça, baseada nos laços com um Brasil imaginário e imaginado. Todos esses elementos que constituem a base do mito foram e ainda estão sendo reforçados com a onda de patrimonialização onde os chefes locais começam novamente a receber atenção, permitindo assim que de Souza e sua família recuperem o poder político perdido desde o começo da descolonização do Benim. ${ }^{68}$

Num mundo globalizado, no qual a escravidão e o comércio de escravos são hoje considerados crimes contra a humanidade, de Souza e sua família foram bem-sucedidos em reforçar sua posição de legitimidade, mesmo se nem sempre nos níveis econômicos e políticos. Essa nova posição de legitimidade é baseada na sua origem brasileira e na celebração do encontro de culturas. Paradoxalmente, os projetos oficiais da UNESCO ajudaram a colocar acento não somente sobre as vítimas do tráfico atlântico de escravos, mas também sobre aqueles que escravizaram e que venderam cativos africanos. Através desse processo de reconstrução da memória do ancestral, endossado por esses projetos oficiais, a família de Souza está gradualmente recuperando seu capital político. Se celebrar a memória do escravagista é geralmente inconcebível do ponto de vista ocidental, no contexto africano isso é possível e relativamente aceito, porque o comércio atlântico de escravos e a escravidão nas Américas não são percebidos como sendo um problema que também diz respeito à África.

${ }^{67}$ Freyre, Casa-Grande \& Senzala, p. 231.

${ }^{68}$ Tall, "De la démocratie et des cultes voduns au Bénin”, e Emmanuelle Kadya Tall, "Dinamique des cultes voduns et du Christianisme céleste au Sud-Bénin”, Cahiers des Sciences Humaines, vol. 31, n. 4, 1995, p. 797-823; Guran, Agudás: os "Brasileiros" do Benim, p. 274-275. 
Além disso, a escravidão e o tráfico em solo africano são parte de uma história bastante recente, onde múltiplos atores foram envolvidos, fazendo com que muitas vezes seja difícil de distinguir as vítimas e os algozes.

Essa valorização da memória de Francisco Félix de Souza, baseada na idéia de que ele não era somente o mais importante mercador de escravos da região mas também o protetor dos fracos, é um feito relativamente bemsucedido entre a população local. No entanto, alguns turistas, particularmente entre os grupos afro-americanos e as populações originárias de Keto e Savalu, contestam fortemente esta reconstrução histórica. 